\title{
BELIEFS, ATTITUDES, AND PERCEPTIONS TOWARDS EVALUATION AND ASSESSMENT OF FUTURE PRIMARY SCHOOL TEACHERS: THE ROLE OF THE PREVIOUS SCHOLASTIC EXPERIENCE
}

\author{
Prof. Ph.D. Antonella NUZZACI, \\ Experimental Pedagogy Department of Human Studies - University of L'Aquila, \\ ITALY, \\ E-mail: antonella.nuzzaci@univaq.it
}

\begin{abstract}
The present study is aimed at exploring perceptions attitudes and beliefs of future primary school teachers towards evaluation during the early stages of their training. It is clear from the literature that, in the initial training phase, assessment is a potentially problematic area of the curriculum, in which past learning experiences seem to have a strong influence on the development of negative attitudes and feelings towards evaluation and forms of verification. Through data collected with different tools, they have been examined perceptions and beliefs regarding the evaluation and assessment of University students, future teachers of primary school in initial training, to try to understand if the previous school experiences had an impact on the general attitude taken towards the assessment and on the intentionality of use of it in the educational field. There is in fact convincing evidence that show how beliefs, values, beliefs and attitudes of future teachers influence cognitive aspects, behavior, decision-making processes and class practices. The study bears witness to this influence above all in the case of previous negative evaluation experiences, which are highly predictive of intentionality of use the assessment in the teaching.
\end{abstract}

Keywords: Assessment; Evaluations; Previous Experience; Preservice Teacher Education; Student Teaching; Teacher Education Preparation;

\section{INTRODUCTION}

The literature shows how attitudes, beliefs and perceptions about assessment are important for the choices and implementation of assessment practices in the school setting (Brown, 2004; Brown et al., 2011; Remesal, 2011; Kitiashvili, 2014), as well as what teachers think of themselves is able to influence their decision-making processes in the teaching-learning paths and their results (Roelofs \& Sanders, 2007). For this reason, it is appropriate to take these beliefs into account in the initial training of teachers in order to avoid that misconceptions, negative experiences and prejudices negatively affect the way of planning and evaluating. The perception of one's own evaluation competence certainly influences the evaluation process (Maba, 2017) and there are numerous factors that can guide or play a role in shaping teachers' perceptions, especially during initial training ( $\mathbf{X} \mathbf{x} \mathbf{x}$, $2019 b$ ), on their evaluation in the classroom. Different ways of evaluating can be traced back to subjective perceptions and different perceptions can influence the teacher's behaviour with specific regard to the judgements he or she makes. The teacher's perception of whether he or 
she is adequate or not in evaluating, as well as his or her beliefs and feelings, have a decisive influence on the intentionality of action; and therefore in carrying out the evaluation in reality ( $\left.{ }^{\mathbf{X X X}}, 2018 ; 2019 b\right)$. This will cause the production of judgments and will, in turn, influence the way the evaluation process is implemented (Astawa et al., 2017).

In fact, if there are many researches aimed at understanding the uses that teachers make of evaluation in the education process and their needs variously expressed in terms of assessment (Metin \& Özmen, 2010), less frequent are those aimed at understanding how previous experiences in terms of evaluation they condition and strongly influence the work of the teacher in initial and in-service training, especially in terms of decision-making processes (Domenici \& Lucisano 2001) and valid and reliable practices (Lucisano, 2003). Equally rare are also researchers directed at investigating how and why the evaluation generates feelings of fear, states of vulnerability and perceived problems of self-esteem and self-efficacy with respect to both learning and teaching.

Even less explored then seems to be the way in which the exposure to previous negative school experiences about the assessment affect the attitudes, beliefs and perceptions of teachers in initial and continuous training.

Just think of how, for example, self-esteem and self-efficacy (LevyVered \& NasserAbu Alhija, 2015) can be conditioned by negative evaluation experiences that have left an indelible trace in individuals.

It is also known how the interactions between these factors have the power to influence the cultural and social meaning and validity of the teaching-learning processes, fueling the resistance to the evaluation process and the rejection that occurs when threats to self-esteem or self-efficacy are high.

Although therefore in the literature there are a series of studies that explore attitudes, perceptions and beliefs with respect to evaluation, rather rare are those examples that refer to the power exercised by previous school experience on the early stages of the training of future primary teachers and their professional development.

This is probably due to the fact that the influence of negative experience on teachers' beliefs is in the effects it produces underestimated.

In this regard, Gimenez (1999) argues that beliefs and biography should be integrated within a reflective approach in the initial training of teachers, since it happens that the latter too often claim to be lacking adequate preparation in the areas of evaluation and measurement (Plake, 1993). In the training of teachers, these areas of expertise to be potentially problematic areas of the curriculum (Akcadag, 2010), which always appear to be growing.

Teachers in initial training, in fact, risk, if not properly trained, to approach the teaching world and to base their future evaluation practices on representations that refer to past experiences related to educational and personal processes, their past school background (when they were pupils), well as to individual and social expectations (such as family expectations, for example), rather than on scientifically based methodological skills. Therefore, if it is true that evaluation practices are able to have a positive impact on training, it seems important to analyze the factors linked to the representations and beliefs possessed by teachers in initial training about the use of evaluation and its tools, in order to understand how they condition future teaching practices to better direct university training on the function they assume in the teaching-learning processes. 
This aspect has been widely explored by Brookhart (2001), who underlined how the difficulties related to the preparation and training of teachers in terms of evaluation and assessment are increasing (Gelbal \& Kelecioglu, 2007; Gencel \& Ozbasi, 2013) and it is now urgent to study these issues, also considering the fact that, although the focus on teacher training has grown at all levels in all countries of the world, a culture of evaluation at school it cannot yet be said to be fully affirmed.

This leads one to think that for many teachers, whether or not they are exposed to evaluation-related training does not always mean, in itself, that they have become literate in it or have been able to remove those obstacles that prevent them from practicing it in appropriate forms. This is also demonstrated by the great intolerance or reluctance that still exists among teachers in training and in service when it talks to evaluation and assessment. Therefore, it may happen that many teachers, for example, arrive at their first teaching assignment after having been exposed to initial training that has fed a not entirely internalized knowledge on important aspects concerning evaluation, knowledge that appears even weaker when it comes to measurement.

In recent years, evaluation and assessment, in terms of techniques, methods, procedures and tools, have assumed an increasingly important role in teacher training curricula and in an increasing number of professionalisation courses, but this has often been more out of necessity than out of real conviction that this area of competence was authentically of interest for their professional development. It has also frequently happened that such programs have not always been able to remove the sedimented rejection (tacit acquisition) of assessment in teachers in training, often own linked to the memory of previous experiences - not always positive - than when they were students, preventing them from applying what they had learned about the assessment ( $\mathbf{x x x x}, 2018 ; 2019)$.

Therefore, if past school experiences seem to have a strong impact on the development of negative attitudes and feelings of apprehension of future teachers towards assessment and exam tests ( $\left.{ }^{\mathbf{X X X X}}, 2018 ; 2019\right)$, then affecting training and intentionality of use in teaching (teaching activities that they will carry out once they enter the school), it is therefore urgent to identify those factors and obstacles that have a repercussion on the correct acquisition of evaluation skills (Schafer, 1991; Plake, 1993) with the intent to try during training to remove them.

\section{Research}

This study aimed to explore the attitude of future primary teachers towards assessment during the early stages of their professional training.

It is clear from the literature that for many trainee teachers, assessment is a potentially problematic area of the curriculum where past learning experiences seem to have a strong impact on the development of negative attitudes and feelings of apprehension towards assessment and exam tests, which in turn could have an impact on the teaching activity that they will carry out in the future.

Through a combination of data collected with different tools, attitudes and perceptions were examined towards the assessment and assessment of students enrolled in the Master's Degree in Primary Teacher Education (a single cycle degree/Combined Bachelor and Master - 5 years) of the Uni, to try to understand if the previous school experiences had an impact on the general attitude taken towards the evaluation during the ongoing training and on the intentionality of use in the didactic field. 
There is convincing evidence indeed that shows how the beliefs, values, beliefs and attitudes of future teachers play an important role in decision making and classroom practices (Calderhead \& Robson, 1991); examining how they emerge and evolve during initial training is of fundamental importance for their professional development of teachers and for "quality" teaching and raising the level of performance in various educational contexts (Nasri et al., 2010). According to Belk and Calais (1998), evaluation allows the teacher to collect information on student progress and the achievement of curricular objectives, constituting the measure by which teaching becomes effective for a certain category of recipients of the training action. The teachers agree that evaluation is, for them, a tool for continuous improvement (Atkins, 1996), even if they do not always make appropriate use of it or have adequate skills $\left({ }^{\mathbf{X x x}}, 2006\right)$. The correlation between assessment and teaching success is ascertained (Atkins, 1996; Oppenheim, 1994) and determines the value of teacher education (Peterson, 2000). The literature shows that teachers' attitude towards evaluation is still substantially very traditional, especially due to the lack of preparation of teachers in applying specific techniques and tools (Akcadag, 2010; Bicak \& Cakan, 2004; Schafer, 1991; Yasar, 2014) and how the assessment is considered by them to be particularly complex (Maden \& Durukan, 2009).

The study described here uses a descriptive model to clarify the relationship between beliefs, perceptions, attitudes and experience of teachers in initial training with regard to assessment and assessment in order to clarify the degree of relationship between two or more variables (Lucisano \& Salerni, 2003). It focuses on the problem of evaluation in teaching, the main source of concern in the professionalization of teachers, linked to the importance of making teaching more effective and efficient and overcoming the difficulties associated with teaching-learning processes.

Describing the beliefs, perceptions, attitudes and experiences of future teachers regarding assessment and understanding what could influence the choice and use of assessment techniques and tools in the school context means gathering important indications to develop more incisive training actions in terms of conducts and behaviors professional ethically and pedagogically corrected in educational settings.

Therefore, it was first validated the hypothesis that previous negative experiences in evaluation influenced the attitude toward it, which has progressively become negative or of refusal, determining over time a lesser opening toward evaluation in the didactic context in terms of intentionality of use.

We then went on to ask the participants to report on their exposure and frequency to negative and / or positive experiences with reference to the evaluation, assuming that the negative ones would have led to negative, closure or refusal attitudes towards the evaluation, mediated by relationship between experiences, beliefs and perceptions.

The study accounted for in this article was preceded by another study, which served as the background for the one described here. The first study had the aim of highlighting the relationship between previous experience in evaluation and the perception of evaluation associated with academic activities by university students enrolled to the Degree Course in Primary Teacher Education.

The first study included:

a correlational analysis that was concerned with studying whether (Hp1) a statistically significant relationship existed between previous negative experience in terms of evaluation (which had prevented the acquisition of specific skills) and perception of the 
evaluation in the university context; $(\mathrm{Hp} 2)$ a statistically significant relationship between previous negative experience in terms of evaluation and acquisition of evaluation skills.

a predictive analysis that went to verify if the previous negative experience towards the evaluation predicted the negative perception of university students in terms of evaluation during the degree course they attend.

Therefore, of the two correlation hypotheses, the first was clearly confirmed: it showed that the greater the negative experience, the greater the negative perception over time. The second hypothesis showed the relationship with other intervening variables and this result should be further explored. Confirmed is also the second hypothesis, which sees the previous scholastic experience foresee the negative perception of the university students in terms of evaluation. This is the background of subsequent studies which is accounted for below.

\section{Aims}

The principal aim of this research was to strengthen the internal studies of the Degree Course in Primary Teacher Education of the Un, in order to gather indications on how to promote greater professional awareness of teachers in initial training in the use of evaluation in educational settings.

It was a matter of investigating which factors, more than others, could adversely affect the attitudes related to the didactic use of evaluation, creating barriers to the use of techniques, criteria, and tools suitable for measuring and evaluating learning. In further studies, which cannot be accounted for here, the relationship between assessment, assessment and methodological-didactic skills has also been studied in relation to the teaching profession that future teachers will carry out on leaving the university.

\section{Methodology}

\section{Participants}

The study participants were 248 university students enrolled in the first year of the Degree Course in Primary Teacher Education of the Uni The survey covered the second semester of the 2016-2017 academic year and the first semester of the 2017-2018 academic year. Of a total of 248 students who participated in the study, 96.96\% (=238) were female and $4.03 \%$ male $(=10)$. The age of the champion ranges from 19 to 45 years. The largest number of students $67.64 \%(=168)$ is placed in the age group ranging from 19 to 26 years. Of the 248 students, $34.67 \%(=86)$ had previously graduated and the remainder graduated. $6.85(=17)$ was already a teacher.

\section{Hipothesis}

Hp1 = There is a significant relationship between general attitude towards evaluation and previous experience

evaluation

$\mathrm{Hp} 2$ = Previous evaluation experience predicts the general attitude towards

$\mathrm{Hp} 3$ = the previous school experience predicts the attitude towards the use of evaluation in a didactic context

$\mathrm{Hp} 3$ = the previous evaluation experience predicts perceived usefulness didactic context

$\mathrm{Hp} 4=$ the previous evaluation experience predicts intention of use in a 
Sub-hypothesis

- $\quad H p 1=$ There is a significant difference in the attitude towards evaluation between younger students ( $<19$ years) and older students $(>40)$

- $\quad \mathrm{Hp} 2=$ There is no significant difference in attitude towards the use of evaluation between students who have a degree and students who have a diploma

Independent variable

- $\quad$ The previous school experience perceived in terms of evaluation

Dependent variables

- $\quad$ General attitude towards evaluation

- $\quad$ Perceived utility

- $\quad$ Positive and negative attitudes towards the didactic use of evaluation

- $\quad$ Intentional use

\section{Data Collecting Instruments}

Questionnaire "Attitude and perception towards evaluation" (15-20 minutes) ( ${ }^{\mathbf{X x x}}$, 2016; Arastaman et al. 2015; Ozan \& Kose, 2013) and Interview structured for previous experience (30 minutes) (Blanchet \& Gotman, 2000).

All study participants were asked to give their informed consent and to provide a voluntary declaration of participation in the research.

\section{Attitudes towards evaluation}

The main tool was aimed at detecting teachers' beliefs and attitudes in initial training with respect to assessment.

It is an instrument aimed at measuring not the "absolute attitudes" towards the evaluation, but the "general" and personal attitudes of university students, which includes, in addition to the skimmed and planned items for the final version, a section for collecting information on the demographic characteristics of the participants and additional observations.

In order to test the validity and reliability of the instrument, it was administered to students coming from similar contexts, selected by age and year of course.

The questionnaire, which consists of five sections, uses a five-point Likert scale. The subjects are called to give their opinion on some statements compared to which they must express their agreement or disagreement.

The items are divided into four sub-scales, whose reliability coefficients were respectively $0.93,0.86,0.78,0.79$ and 0.82 , with an overall Cronbach's Alpha of 0.834 .

This allowed us to conclude that the tool had satisfactory reliability in assessing students' attitudes towards evaluation and assessment.

In order to assess the relevance of each factor, they were made comparisons within subject between different sub-scales of each section and a descriptive analysis was performed on all four scales of the instrument, though significant differences between the sub-scales emerge in the aspects that characterize the experience $[F(2,268)=438,133 ; \mathrm{p}<.001]$. 


\section{Previous self-reported evaluation experiences}

In order to measure the frequency of previous negative experiences in evaluation previous studies were taken into account. The scale measured the number of episodes and exposure to different negative experiences. To determine whether the tool regarding the evaluation experiences was valid, it was subjected to an analysis of the main components using a direct SPSS rotation, which allowed to extract three factors with eigenvalues of 5.16, 1.88 and 1.26 . The set of factors explained $49.84 \%$ of the variance in the data. Component 1 contained seven elements related to the frequency of negative experiences in the school field concerning different school grades, Component 2 contained six elements related to one's experiences with different subjective elements and Component 3 contained six elements related to perceptions. We have defined these factors as "Evaluation experiences" $(\alpha=.74)$, "Negative evaluation experiences" $(\alpha=0.759)$ and "Perceptions" $(\alpha=0.67)$. The factors were positively correlated, $\mathrm{r}=.68, \mathrm{p}<.001$.

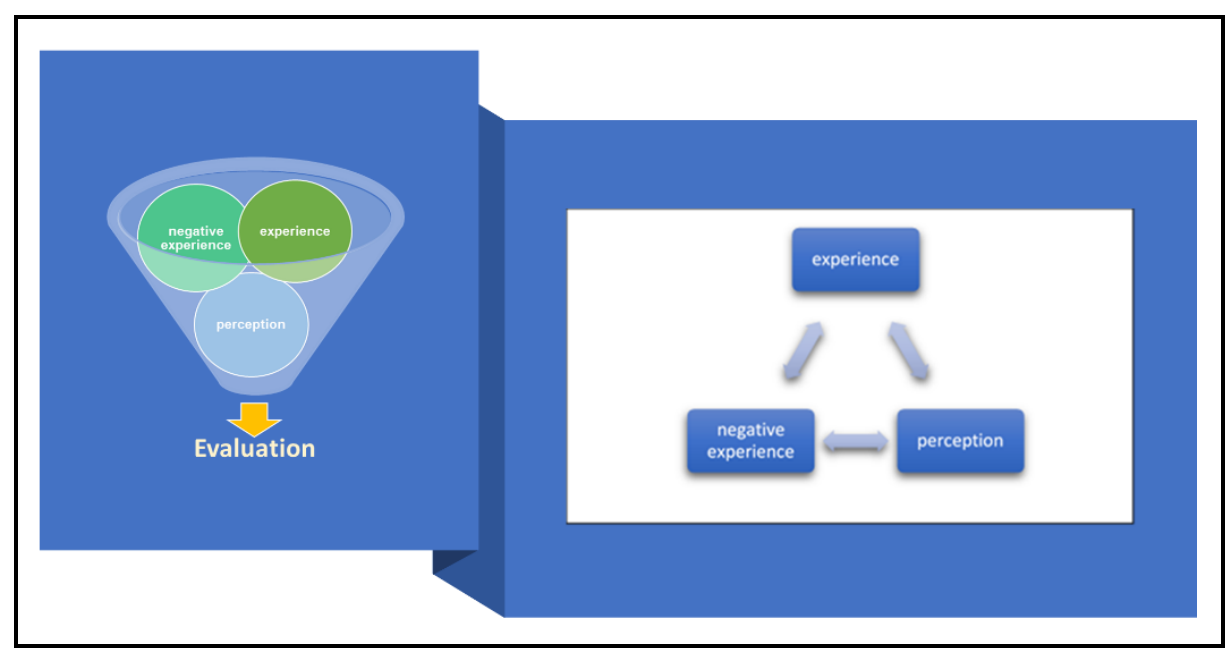

Fig. 1 - Mediation model that describes the effect of previous evaluation experiences with elements on the attitude through perception. The total effect is listed in parentheses; all regression values are not standardized

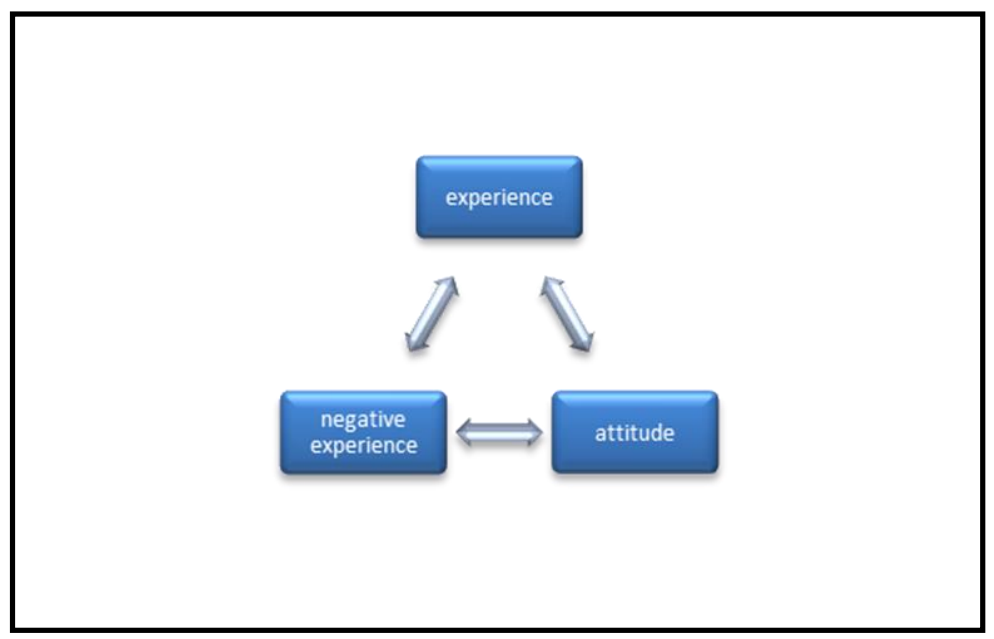


Fig. 2 - Mediation model that describes the effect of experiences and cultural elements. The total effect is listed in parentheses; all regression values are not standardized

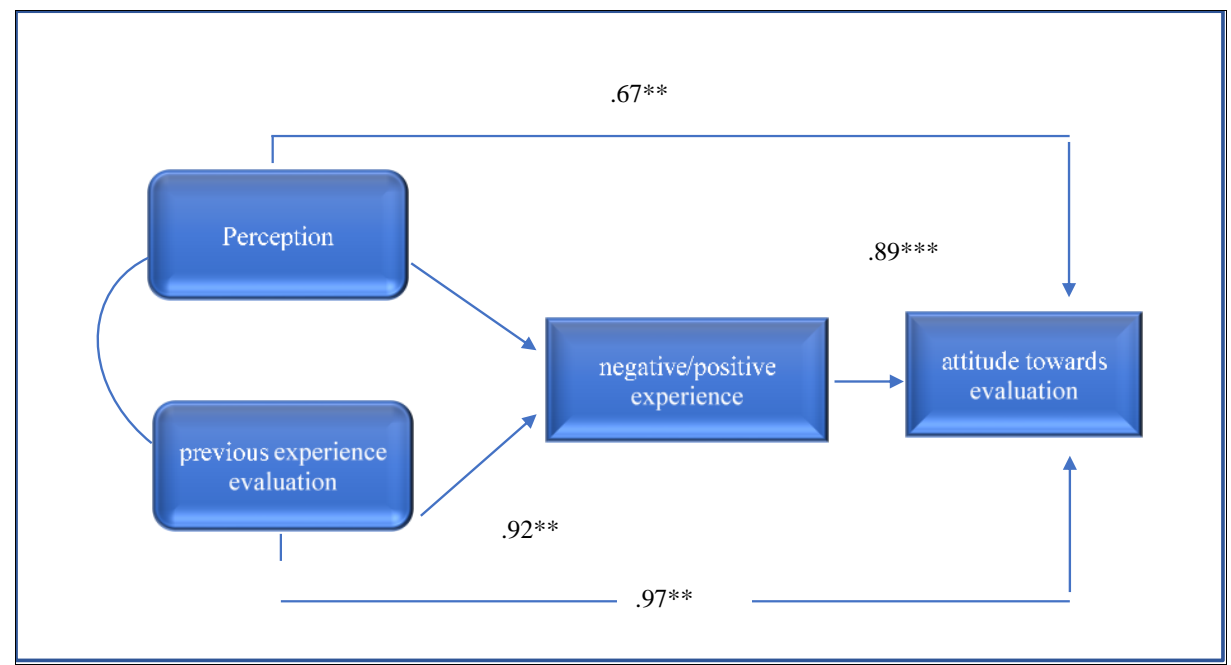

Fig. 3 - Path model that describes the effect of both components of previous evaluation experiences and attitude towards evaluation

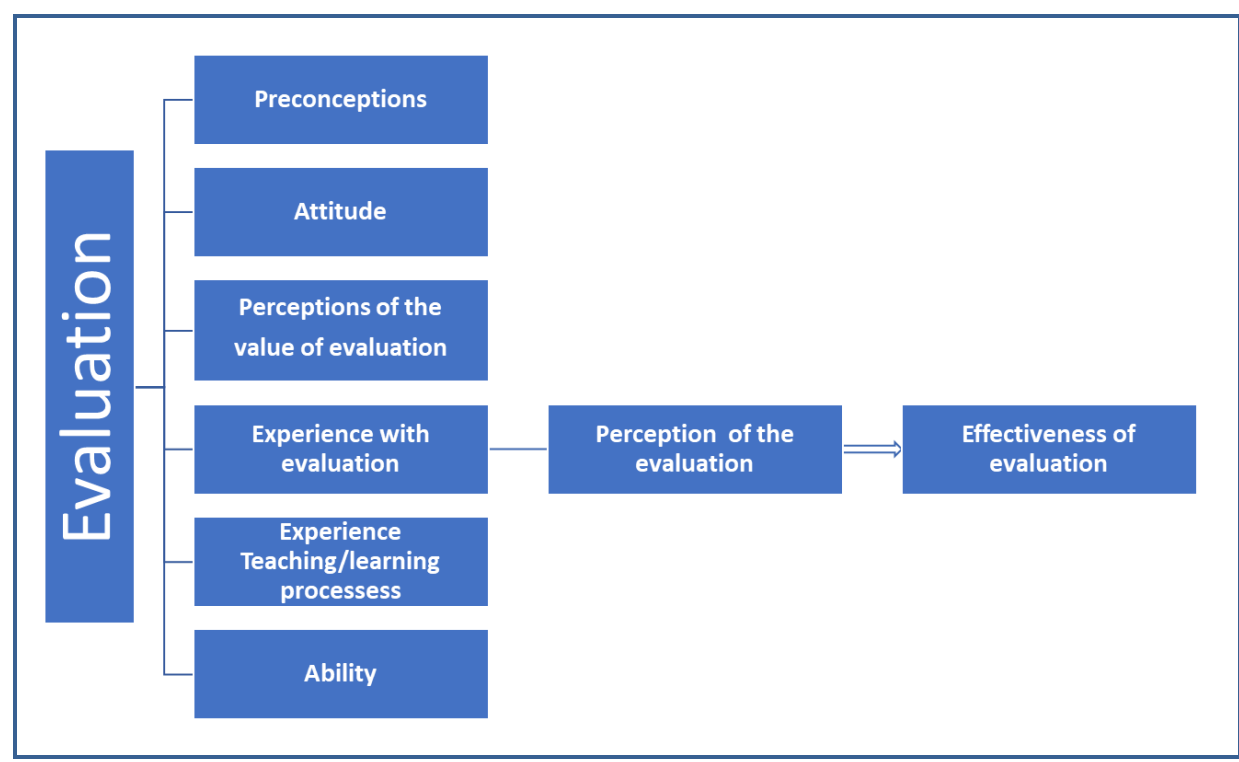

Fig. 4 - Perception of the evaluation and effectiveness of evaluation

\section{Results}

Descriptive analysis: attitude towards evaluation

Based on the results, the composite variables were calculated as the average values of the elements involved in each construct. The descriptive statistics included: means, standard deviation and correlation coefficients with model fit and regression, factorial analysis and varimax rotation. 
A correlational analysis was conducted relating to the variables considered in the key hypotheses. A positive mean correlation was found with a $r$ value of $.866(p<.01)$.

Pearson's correlation was conducted to examine the first research question relating to the relationship between the general attitude towards evaluation and school experience in evaluation, also in reference to the exploration of the attitude towards didactic use and identification of any significant difference in the importance and perceived usefulness between younger students ( $<18$ years) and older students $(>40)$ and between those who already have a degree, as well as the intentionality of use.

A multiple linear regression analysis was then conducted to determine the contribution of past evaluation experience on dependent variables (general attitude towards evaluation and assessment).

The analysis shows that there is a substantial positive correlation between general attitude towards evaluation and evaluation experience $(r=.97, p<.01)$ and attitudes of use and age $(\mathrm{r}=.69, \mathrm{p}<.01)$ and between attitude towards educational use $(\mathrm{r}=.83, \mathrm{p}<.01)$, as well as between perceived utility $(r=.91, \mathrm{p}<.01)$ and intentionality of use $(r=.85, \mathrm{p}<.01)$.

Further analysis showed a moderate correlation between past experience and intentionality of use $(\mathrm{r}=.85, \mathrm{p}<.01)$ and educational use $(\mathrm{r}=.64, \mathrm{p}<.01)$, as well as a very high correlation between intentionality of use and attitude towards educational use $(\mathrm{r}=.86, \mathrm{p}$ $<.01)$.

Narrow appears the link between previous experience and general attitude and between previous experience and attitude to a didactic use of evaluation, which implies that as the negative previous experience towards evaluation tends to grow negative general attitude and perception.

To perform the regression analysis, the existence of high correlation values between the variables $(\mathrm{r}=92)$ was examined.

The index score of the general attitude towards evaluation was taken as a dependent variable and the scores related to previous evaluation experience were considered as independent variables.

The results show that the evaluation experience in the school history of future teachers, together with the sub-dimensions, explains approximately $57 \%$ of the variance of the index score of the general attitude towards evaluation $(R=0.689, R 2=0.42, p<.01 \mathrm{~F}$ $(4.275)=45.315 \mathrm{p}=0.000)$.

The corrected R2, which corresponds to the model in the population, suggests that the independent variables intersect the dependent variable at the average level $(\mathrm{R} 2=383)$.

According to the standardized regression coefficients $(\beta)$, the relative order of importance of the variables with respect to experience is 'use measurement instruments' $(\beta=$ .261), 'be familiar with the basic concepts of evaluation' $(\beta=209)$ and 'use alternative and/or innovative measurement instruments' $(\beta=173)$, while 'develop measurement instruments' does not appear significant.

The study also used factorial analysis and varimax rotation component analysis to clarify the structure of attitudes towards evaluation and its use in a didactic context: a didactic use of evaluation is closely related to an ambivalent attitude in terms of values mediated by previous experience. 


\section{Analysis of the results}

The SPSS (Package Statistical for Social Scientists) version 15.1 was used for data processing.

The descriptive analysis of the sample highlights how past experiences in evaluation influence the attitudes of future teachers towards evaluation and how their frequency in terms of exposure to negative ones correlates positively with attitude; so much is this that a university student who has experienced negative experiences in terms of evaluation also has attitudes of closure or refusal of evaluation (mediated by perception) which tend to persist over time and which lead him to consider it not very useful (perception of usefulness), especially on the level of intentionality of use in a school context.

Exposure to previous negative evaluation experiences is also tendentially associated with a high negative attitude towards assessment tools with a perceived experience that mediates the relationship between negative experiences and negative attitudes.

On the other hand, those who have benefited in the school past of favourable environments and experiences in terms of evaluation seem more willing to use it profitably in the school context and to use more innovative evaluation tools (the latter dimension which should be further investigated in terms of positive attitudes towards students and teaching).

The data therefore suggest how the experiences (self-reported), containing precise elements / events, reliably predict the attitude towards the intentionality of use (self-reported) of the evaluation at school; in fact, the indirect effect of negative / positive experiences on the attitude in the evaluation through perception resulted in the analysis more robust than the indirect effects of other factors.

The students' comments on evaluation methods and tools mainly concerned the distance that often exists between what is declared in the teaching session on the evaluation and what instead is achieved, as, for example, in the case of teaching programs that frequently present a certain divergence between what is written and what is actually requested by the teachers, both in written and oral modalities. Examining the data collected, in the context of L, on the conceptions that future primary teachers have of the evaluation in relation to teaching practices, common representations emerged in the literature as well as a series of so-called "naive" knowledge ( $\left.{ }^{\mathbf{x x x}}, 2018\right)$, directly attributable to the negative individual experiences lived by the interviewees, in particular during the school experience.

The overall results show that the reduction of a negative attitude towards assessment is of decisive importance in the initial training of teachers ( $\left.{ }^{\mathbf{x x x}}, 2018\right)$, since the less negative attitudes are present, the more the favorable disposition to correctly use the assessment in a didactic sense will be increased, avoiding drifts of refusal or ambiguity in favor of balanced attitudes and rigorous behavior on a methodological level.

The previous negative evaluation experience appears to be an important predictor of the attitude which, on an in-depth examination, reveals, specifically, a data that is only apparently ambivalent: university students, who perceived themselves as "failed students" and exposed to a "Unjust evaluation", presented, in some cases, a higher intentionality of use in a didactic context, explained by perception. 


\begin{tabular}{|l|l|l|l|l|}
\hline \multicolumn{1}{|c|}{ Scale } & Eigenvalues & Reliability & $\begin{array}{l}\text { Correlation } \\
\text { Component }\end{array}$ & $\begin{array}{l}\text { Correlation } \\
\text { Component }\end{array}$ \\
\hline $\begin{array}{l}\text { Component 1 } \\
\text { "Evaluation } \\
\text { experiences" }\end{array}$ & 5.16 & $\alpha=.748$ & Component 2=.898 & $\begin{array}{l}\text { Component } \\
3=.952\end{array}$ \\
\hline $\begin{array}{l}\text { Component 2 } \\
\text { "Negative evaluation } \\
\text { experiences" }\end{array}$ & 1.88 & $\alpha=.759$ & Component $1=.862$ & $\begin{array}{l}\text { Component } \\
3=.876\end{array}$ \\
\hline $\begin{array}{l}\text { Component 3 } \\
\text { "Perceptions" }\end{array}$ & 1.26 & $\alpha=.679$ & Component $1=.924$ & $\begin{array}{l}\text { Component } \\
2=.962\end{array}$ \\
\hline
\end{tabular}

Table 1. Previous self-reported evaluation experiences

The study provided a further deepening, which consisted of two phases: carry out of a scale on previous experience in terms of evaluation and a history interview (Blanchet \& Gotman, 2000) on school life with the interviewed, to understand how the future teacher had gained a negative or positive perception of the assessment over time. In the first phase, the student teachers were asked to give an account of the degree and number of negative or positive experiences lived in the school path, while in the second phase they have been asked to conceptualize the critical episodes or accidents, also with the help of metaphors, from their school history compared to what is reported in the previous scale. The scale and guide for the interview were designed with reference to the literature revised. The interview data were used to explore some central aspects of the history of school life of the student teachers and to understand how they were related to the aptitude and perception of the assessment. Methods of data collection included the interview after the carry out of the scale with the student teacher, the recording of interviews and the analysis of the material by external evaluators.

The results showed how the impact of the previous experience of the student teachers affect their conceptualization of the assessment is very strong, showing how it shapes their perception in different ways, also reference to models of teaching and teacher. They testify how the evaluation is strictly connected to the other teaching functions and exercise its influence even after some time. Moreover, some teachers interviewed (n. 32) declare that a part of assessment knowledge and skills depend largely on the correct attitudes that are assumed in teaching and how a teacher can really guide a pupil to learn. This implies, in their opinion, that use assessment as a positive and illuminating process only when understands what is didactically doing and why it is being done.

Most of the existing literature indeed notes that the prior scholastic experience lived by student teachers has a binding effect on learning of the assessment skills in University context when they are trained professionally to become a teacher. It is however that professional training can do a lot to overcome the powerful effects of previous experience, also because an interactive vision of the training process maintains that these experiences 
exert a certain influence but do not totally determine social and cultural results (Zeichner and Gore 1990). The research also highlights how the history of school life can be used as a teaching resource for the teacher. Collay (1998) goes beyond the premise that life history has the power to shape teachers' beliefs about their roles and practices by claiming the importance of training in teaching learning. The results obtained show how school life and training influence each other.

Teaching is not only shaped by the scholastic history of life, and its reinterpretation offers new opportunities to make sense of those scholastic stories. Some authors (Sikes and Troyna 1991) argue, in this sense, that the use of a biographical approach in initial teacher education is transformative, contributes to capitalizing on experiences and perspectives and to using them as resources for teaching; it can be considered as a window on the world and on the vision of oneself. They also argue that previous scholastic history opens up new options for the future and group stories provide clarifying effects (Woods and Skies 1987).In summary, If it is true that it is important for university students to avoid entering the teaching profession with negative opinions, poorly founded attitudes and naive beliefs, the challenge for teacher trainers can only be to remove or interrupt these "circles vicious", culturally inappropriate, to promote scientifically based professional habitus.

As for other professionals, teachers are expected to carry out their educational functions without prejudice, without neglecting important aspects of their professionalism, which requires the acquisition of appropriate methodological skills, but also the assumption of an ethically appropriate professional attitude, an "evaluation habitus" aimed at increasing teaching effectiveness through continuous development: evaluation is linked to education and its problems!

As for other professionals, teachers are expected to carry out their educational functions without prejudice, without neglecting important aspects of their professionalism, which requires the acquisition of appropriate methodological skills, but also the assumption of an ethically appropriate professional attitude, an "evaluation habitus" aimed at increasing teaching effectiveness through continuous development: evaluation is linked to education and its problems!

Assessment literacy in fact includes families of skills and knowledge that are indispensable to identify, select or create forms of assessment optimally designed for various purposes and to examine and use evidence of a different nature with a view to making appropriate decisions aimed at advancing students' learning (Kahl et al. 2013), accelerating their commitment and success.

It is first of all useful here to remember how the teacher must first of all possess precise skills in order to be able to identify what (what learning) is being evaluated (training objectives), why and how best to do it, i.e. which methods, tools and techniques should be used to detect the phenomenon concerned, having certain references (evaluation criteria) and being aware of the problems that could occur in the evaluation process, as well as how to prevent them from occurring (Stiggins, 1995; Stiggins, 1997; Stiggins, 1991; Stiggins, 1988), making judgments, always provisional, on what has been detected.

In fact, according to Mertler (2004), experienced assessment teachers are able to recognize both the value of assessment and the value of measurement, taking care of the communicative practices of judging and carefully choosing the assessment methods to be used to gather credible information about pupils' academic performance and other variables interacting with them, as well as being able to document and communicate them. 
If we do not want to run into a sort of "systemic hypocrisy", which prevents the emergence of a real "culture of evaluation", capable of translating intention into action and awareness of and action, instead of remaining a mere declaration of intent, teachers must be equipped of general routine competences concerning measurement, but above all the coherence of the functions and the didactic actions implemented.

\section{Conclusions}

Although the picture outlined so far is certainly limited compared to what may be contained in the domain of the perception of the evaluation, it can be of some use for those who want to start confronting the authentic problems of education and teacher professionalism, but above all on the importance the acquisition of "assessment and assessment skills". The extent of the professional (cultural, social and political) role played by teachers and the responsibility for an adequate assessment of pupils' learning can be described in terms of activities that take place before and during education, which require teachers to have adequate assessment skills, as well as sufficient time and resources to perform their institutional tasks. In this context, the future teacher is called upon to acquire adequate assessment skills that allow him to take on a set solid methodology to intervene in complex school contexts and to help him generate proposals corresponding to the needs of the recipients, also in an attempt to fulfill the real professional needs of contemporary society. This opens up the prospect to the continuous improvement of the teaching profession, the reformulation of new curricular objectives and an innovative teaching perspective.

Identifying teachers beliefs about evaluation and assessment in initial training phase would have paramount importance as it could inform the teacher trainers about the specific area of weakness that the education program should target on and the means through which the targets could be achieved. On this regard, the result of this study indicated that the student-teachers have traditional beliefs of evaluation and assessment as well as teaching and learning. Furthermore, they tend to prefer traditional teacher-centered evaluation approach which is consistent with their conceptions of evaluating and assessment. This result seems to support the conclusion that teachers' beliefs about teaching shape their evaluative and instructional decisions in the classroom. The teacher education programmes should target on influencing the deep-seated beliefs of these student-teachers who are in the early stages of their training. This means that student teachers need to be exposed to a learning environment that deconstruct their existing beliefs, as a pre-requisite for implementing the mastery in the evaluation and assessment. The first and foremost remedy through which the teacher training should create opportunities for student-teachers is that is to initiate reflection from their experience as students. If student-teachers see in use appropriate evaluating techniques, methods, and strategies modeled within their own training, they will be more comfortable with assessment principles and more likely will be more available to adopt valid and reliable measuring instruments in their future classrooms.

\section{Conflict of Interest Statement}

The author declares that the research was conducted in the absence of any commercial or financial relationships that could be construed as a potential conflict of interest. 


\section{References:}

[1] Akcadag, T. (2010). Ogretmenlerin ilkogretim programindaki yontem, teknik, olcme ve degerlendirme konularina iliskin egitim ihtiyaci [Teachers' need for training on assessment and evaluation methods and techniques]. Bilig, 53, 29-50.

[2] Arastaman, G., Yildirim, K., \& Dasci, E. (2015). Development of measurement and evaluation scale: a study of reliability and validity. Pamukkale University Journal of Education, 38(2), 219-228.

[3] Arastaman, G., Yildirim, K., \& Dasci, E. (2016). The relationship between teachers' attitude toward measurement and evaluation and their perceptions of professional well-being. Eurasian Journal of Educational Research, 62, 77-96, http://dx.doi.org/10.14689/ejer.2016.62.6

[4] Atkins, A. O. (1996). Teachers' opinions of the teacher evaluation process (ERIC Document Reproduction Service No. ED 398 628).

[5] Bicak, B., \& Cakan, M. (2004). Lise ogretmenlerinin sinif ici olcme ve degerlendirme uygulamalarina donuk gorusleri [Views of high school teachers about practices of asessment and evaluation in classroom]. Orta Ogretimde Yeniden Yapilanma Sempozyumu'nda sunulmus bildiri, Milli Egitim Bakanligi, Ankara.

[6] Blanchet, A., \& Gotman, A. (2000). L'indagine e i suoi metodi: l'intervista (1992). XXXXXXXXXXX. Roma: Kappa.

[7] Briscoe, C. (1993). Using cognitive referents in making sense of teaching: a chemistry teacher's struggle to change assessment practices. Journal of Research in Science Teaching, 30(8), 971-987. https://doi.org/10.1002/tea.3660300812.

[8] Brookhart, S. M. (2001). Successful students' formative and summative uses of assessment information. Assessment in Education, $8(2), \quad$ 153-169, https://doi.org/10.1080/09695940123775

[9] Brown, G. T. L. (2004). Teachers' conceptions of assessment: implications for policy and professional development. Assessment in Education: Principles, Policy \& Practice, 11(3), 301-318, http://dx.doi.org/10.1080/0969594042000304609.

[10]Brown, G., Lake, R., \& Matters, G. (2010). Queensland teachers' conceptions of assessment: the impact of policy priorities on teacher attitudes. Teaching and Teacher Education, 27(1), 210-220, https://researchspace.auckland.ac.nz/docs/uoa-docs/rights.htm

[11]Calderhead, J., \& Robson, M. (1991). Images of teaching: student teachers' early conceptions of classroom practice. Teaching \& Teacher Education, 7(1), 1-8, https://doi.org/10.1016/0742-051X(91)90053-R

[12]Collay, M. (1998). Recherche: teaching our life histories. Teaching and Teacher Education, $14(3), 245-255$.

[13]Domenici, G., \& Lucisano, P. (2011). Valutazione, conoscenza, processi decisionali: dibattito. Journal of Educational, Cultural and Psychological Studies (ECPS Journal), 3, 147-167, https://www.ledonline.it/index.php/ECPS-Journal/

[14]Dwyer, C. A. (2007). The future of assessment: shaping teaching and learning. Mahwah, NJ: Lawrence Erlbaum Associates.

[15]Finnegan, R. S. (2013). Linking teacher self-efficacy to teacher evaluations. Journal of Cross$\begin{array}{llll}\text { Disciplinary } \quad \text { Perspectives in } & \text { Education, } & \text { 18-25, }\end{array}$ https://pdfs.semanticscholar.org/6c63/2b28ee3ba138637fba69a3fb563bcabc7fcb.pdf

[16]Gelbal, S., \& Kelecioglu, H. (2007). Ogretmenlerin olcme ve degerlendirme yontemleri hakkindaki yeterlik algilari ve karsilastiklari sorunlar [Teachers' perception of competency about assessment and evaluation methods and difficulties]. Hacettepe Universitesi Egitim Fakultesi Dergisi, 33, 135-145.

[17]Gencel, I. E., \& Ozbasi, D. (2013). Investigating prospective teachers' perceived levels of competence towards measurement and evaluation. ilköğretim Online, 12(1), 190-201.

[18]Gimenez, T. (1999). Reflective teaching and teacher education contributions from teacher training. Linguagem \& Ensino, 2(2), 129-143.

[19]Joram, E., \& Gabriele, A. (1998). Pre-service teachers' prior beliefs: transforming obstacles into opportunities. Teaching and teacher education, 14(2), 175-191. 
[20]Karaca, E. (2004). Student teachers' perceptions of competencies on assessment and evaluation. Eskisehir: Anadolu Universitesi Yayinlari.

[21]Karp, G. G., \& Wood, M. L. (2008). Pre-service teachers' perceptions about assessment and its Implications. Journal of Teaching in Physical Education, 27(3), 327-346.

[22]Kitiashvili, A. (2014). Teachers' attitudes toward assessment of student learning and teacher assessment practices in general educational institutions: the case of Georgia. Improving Schools, 17(2), 163-175. http://dx.doi.org/10.1177/1365480214534543.

[23]Knowles, J. G. (1992) Models for understanding preservice and beginning teachers' biographies: illustrations from case studies. In I. Goodson (ed.), Studying teachers' lives (pagg. 99-152). London: Routledge.

[24]Levy-Vered, A., \& Nasser-Abu Alhija, F. (2015). Modelling beginning teachers' assessment literacy: the contribution of training, self-efficacy, and conceptions of assessment. Educational Research and Evaluation, 21(5-6), 378-406, doi: 10.1080/13803611.2015.1117980

[25]Lortie, D. C. (1975). Schoolteacher: a sociological study. Chicago, IL: The University of Chicago.

[26]Lucisano, P. (2003). Validità e affidabilità delle pratiche valutative: a proposito del Progetto Pilota 2. Cadmo, 11(2), 37-56.

[27]Lucisano, P., \& Salerni, A. (2003). Metodologia della ricerca in educazione e formazione. Roma: Carocci.

[28] Maba, W. (2017). Teacher's Perception on the implementation of the assessment process in 2013 curriculum. International journal of social sciences and humanities, 1(2), 1-9.

[29]Maden, S., \& Durukan, E. (2009). Turkce dersi ogretmenlerinin olcme-degerlendirmeye iliskin algilari [Turkish language teachers' perception on assessment and evaluation]. Milli Egitim, 190, 212-233.

[30]McDiamid, G. W. (1990). Challenging prospective teachers' beliefs during an early field experience: a quixotic understanding? Journal of Teacher Education, 41(3), 12-20.

[31] Metin, M., \& Özmen, H. (2010). Determination of science and technology teachers' in-service education (inset) needs on performance assessment. Kastamonu Education Journal, 18(3), 819-838

[32]Nespor, J. (1987). The role of beliefs in the practice of teaching. Journal of Curriculum Studies, 19(4), 317-328.

[33] Oppenheim, C. (1994). Encouraging evaluation utilization by preserving teacher self-esteem. Washington, DC: Center for Research in Educational Accountability and Teacher Evaluation. (ERIC Document Reproduction Service No. ED377192)

[34]Ozan, C., \& Kose, E. (2013). Adaptation of attitudes toward Educational Measurement Inventory (ATEMI) to Turkish. E-International Journal of Educational Research, 4(2), 29-47.

[35]Peterson, K. D. (2000). Teacher evaluation: a comprehensive guide to new directions and practices (2nd ed.). Thousand Oaks, CA: Corwin Press.

[36]Plake, B. S. (1993). Teacher assessment literacy: teacher's competencies in the educational assessment of students. Mid-Western Educational Researcher, 6(2), 21-7.

[37]Popham, W. J. (2011). Assessment literacy overlooked: a teacher educator's confession. The Teacher Educator, 46(4), 265-273, https://doi.org/10.1080/08878730.2011.605048

[38] Remesal, A. (2011). Primary and secondary teachers' conceptions of assessment: a qualitative study. Teaching and Teacher Education, 27(2), 472-482, http://dx.doi.org/10.1016/j.tate.2010.09.017

[39] Schafer, W. D. (1991). Essential assessment skills in professional education of teachers. Educational Measurement: Issues and Practice, 10(1), 3-6, https://doi.org/10.1111/j.17453992.1991.tb00170.x

[40]Schön, D. L. (1983). The reflective practitioner. How professionals think in action. New York: Basic Books Inc.

[41] Shepard, L. A. (2000). The role of assessment in a learning culture. Educational Researcher, 29(7), https://nepc.colorado.edu/sites/default/files/TheRoleofAssessmentinaLearningCulture.pdf 
[42] Sikes, P., \& Troyna, B. (1991). True stories: A case study in the use of life history in initial teacher education. Educational Review, 43(1), 3-16.

[43] Stiggins, R. J. (1991). Assessment literacy. Phi Delta Kappan, 72(3), 534-539.

[44] Struyven, K., Dochy, P., \& Janssens, S. (2005). Students' perceptions about evaluation and assessment in higher education: a review', assessment \& evaluation. Higher Education, 30(4), 325-341. doi: 10.1080/02602930500099102

[45]Woods, P. C., \& Skies, P. J. (1987). The use of teacher biographies in professional selfdevelopment. In F. Todd (Ed.), Planning continuing professional development (pp. 161- 180). London: Croom Helm.

[46] Wubbels, T. (1992). Taking account of student teachers' preconceptions. Teaching and Teacher Education, 8(2), 137-149. doi: 10.1016/0742-051X(92)90004-M

[47]Yan, Z. (2014). Predicting teachers' intentions to implement schoolbased assessment using the theory of planned behaviour. Educational Research and Evaluation, 20(2), 83-97, https://doi.org/10.1080/13803611.2013.877394.

[48] Yasar, M. (2014). Developing the scale of attitude towards the course of assessment and evaluation in education. Egitim Bilimleri Arastirmalari Dergisi Uluslararasi E- Dergi, 4(1), 258-279. 